Removal of Organic Pollutants from Tofu-Processing Wastewater through Anaerobic Treatment Process with Short Hydraulic Retention Time

\title{
Removal of Organic Pollutants from Tofu-Processing Wastewater through Anaerobic Treatment Process with Short Hydraulic Retention Time
}

\author{
Darwin, Satria Purwanto, Ridho Rinaldi
}

Department of Agricultural Engineering, Syiah Kuala University, Banda Aceh 23111, Indonesia

Corresponding author: darwin_ae@unsyiah.ac.id

Department of Agricultural Engineering, Syiah Kuala University, Banda Aceh 23111, Indonesia

Anaerobic digestion of tofu-processing wastewater was carried out in batch and continuous systems. The performance of a continuous system was investigated at the hydraulic retention time of 10 days and the organic loading rate of $0.752 \mathrm{~kg} / \mathrm{m}^{3}$ day. Anaerobic digestion operated in the continuous system generated higher biogas yield (123 mL/g VS) compared with the batch system ( $43 \mathrm{~mL} / \mathrm{g}$ VS). The assessment of biodegradation efficiency showed that a continuous reactor had higher VS reduction $(76 \%)$ in comparison with the batch reactor, which only had $57 \%$ VS reduction. The results of the current study also revealed that anaerobic digestion applied for treating the tofu-processing wastewater could recover $\mathrm{pH}$ culture from the acidic condition $(\mathrm{pH} 5)$ into the level close to the neutral condition ( $\mathrm{pH}$ 6.6). The current study is highly significant for the development of applied technology for protecting environment.

Keywords: anaerobic digestion, tofu-processing wastewater, low pH, OLR, HRT. 


\section{Introduction}

Food processing industries have been growing rapidly in many places. Currently, the industries have been classified as vital industries if they are responsible for supplying food to the consumers. The presence of the food-processing industries in some places could normallyprovide some benefits to the society such as enhancing economic growth by providing new jobs for people and increasing food production to secure the food stock. However, some negative effects generated from the industries such as water and soil pollution should not be neglected (Kanu et al., 2011). This is due to the fact that food-processing industries produce tons of organic wastes. If the wastes generated are directly disposed to the land or water body, they could damage the environment and destroy an ecosystem in water bodies (Carucci et al., 2005).

Some conventional food processing industries that do not have sufficient and feasible facilities to treat organic wastes tended to dispose the wastes into a water channel and local drainage. Regular and/or continuous disposals of organic wastes into a water body could reduce dissolved oxygen and increase biological and chemical oxygen demand in the water, and thereby could lower the surface water quality (Burkholder et al., 2007; Gyawali et al., 2012). The polluted water would affect the health and life of human beings living close to the industry(Chukwu, 2009).

Besides, contaminated water could stimulate the growth of microbial activity in the water (Cabral, 2010). Thus, the condition would have negative effects on humans as some microbes may be pathogens that could spread out diseases to the ones consuming contaminated water(Solomon et al., 2002; Islam et al., 2004). One of the food-processing industries that potentially contribute to environment pollution is the tofu-processing industry. This occurs as the industry may discharge the effluent having a high concentration of organic wastes (Lay et al., 2013).

Research and development on the treatment of tofu-processing wastewater is significant as the finding and technology developed could be directly applied to cut off pollution caused by the direct disposal of the wastewater. One of the technologies that could effectively be applied to treat tofu-processing wastewater is anaerobic digestion technology. This is due to the fact that anaerobic digestion is an established technology that has been widely used for treating organic wastes (Alkaya and Demirer, 2011; Darwin et al., 2018a). The technology could effectively reduce organic materials and convert them into biogas that can be used as renewable energy (Alkaya and Demirer, 2011; Mata-Alvarez et al., 2000; Mir et al., 2016).

Anaerobic digestion is a complex process that consists of several stages (i.e.,acidogenesis, acetogenesis and methanogenesis) which involve different types of microorganisms (Adekunle and Okolie, 2015). Therefore, maintaining and/or controlling appropriate operating conditions (i.e., $\mathrm{pH}$, temperature) are crucial for supporting anaerobic microbes to complete the biodegradation process (Chae et al., 2008; Darwin et al., 2018a). Operational parameters such as organic loading rate (OLR) and hydraulic retention time (HRT) should also be taken into consideration when the process of anaerobic digestion is carried out under a continuous system (González-Fernández et al., 2013; Darwin et al., 2017).

Some studies have revealed that anaerobic digestion of wastewater could be effectively operated at the ranges of HRT between 25 and 30 days (Lim et al., 2012). Even if those HRT ranges are effective for reducing organic materials in wastewater (Lim et al., 2012), the treatment would be ineffective when the anaerobic digesters receive too much wastewater that should be treated. Thus, the current study aimed to evaluate anaerobic treatment of tofu-processing wastewater with short HRT, and to investigate whether short HRT and high OLR applied could remove organic materials and enhance the conversion rate of organic pollutants in tofu-processing wastewater. Therefore, the treatment of tofu-processing wastewater would be accomplished quicker. 


\section{Materials and Methods}

\section{Wastewater collection}

Tofu wastewater used for this experiment was taken from the tofu-processing industry at Punge Blang Cut, Banda Aceh. The wastewater was stored in the fridge at the temperature of $5^{\circ} \mathrm{C}$ prior to the experiment. No inoculums was used for this experiment as the research was carried out to treat tofu-processing wastewater directly through the anaerobic process. The process of anaerobic digestion conducted in this experiment was dependent on the presence of microbes in the wastewater. Thus, the performance of anaerobic digestion would be based on the operating conditions used.

\section{Reactor operation}

Batch processes of anaerobic digestion were carried out in a bioreactor with 3 litre of the working volume. During the experiment, the temperature of the bioreactor was maintained at $35^{\circ} \mathrm{C}$ by using a water bath computerised respirometer. Batch experiments were carried out in triplicates. The duration of the batch experiments was based on the point at which the anaerobic digester stopped to produce biogas completely as suggested by a previous study (Darwin et al., 2016a). Daily samples taken before and after the incubations were analysed to assess the performance of the batch process. In this study, the batch experiments were concluded and stopped on day 15 of incubation.

A semi-continuous reactor was operated in a steady state condition in which the temperature was controlled under the mesophilic condition at $35^{\circ} \mathrm{C}$. The working volume of the reactor was 3 litres, and the hydraulic retention time (HRT) applied was 10 days. The organic loading rate applied in this semi-continuous operation was $0.752 \mathrm{~kg} / \mathrm{m}^{3}$ day. In order to ensure the process of anaerobic digestion running properly, $\mathrm{pH}$ of the culture was measured periodically during the feeding and the wasting period. The influent and effluent samples were taken every day for the analysis. To accomplish a steady state condition, the semi-continuous reactors were operated for 30 days.

\section{Analytical methods}

All samples obtained from the influent and effluent were analysed for $\mathrm{pH}$, total solids (TS) and volatile solids (VS), total dissolved solids (TDS), total potassium (K), phosphorous (P), chemical oxygen demand (COD) and total kjedahl nitrogen (TKN). All analysis procedures were carried out according to the standard methods(APHA, 2012). The biogas production rate was measured based on the volume of gas produced per day, and the biogas yield was measured based on the cumulative gas produced per gram volatile solids added (Parawira et al., 2008; Darwin et al., 2014). In order to evaluate the effectiveness of the degradation during the process of anaerobic digestion, COD removal and VS reduction were analysed and calculated according to the formula used and mentioned in the previous studies (Joanne, 1991;Darwin et al., 2016b).

\section{Results and Discussion}

\section{Batch operation}

In order to evaluate to what extent tofu-processing wastewater influences the behaviour of microbial activities in a closed culture system, anaerobic treatment process was carried out under the batch system. The characteristics of the anaerobic treatment process of tofu-processing wastewater operated in the batch system are presented in Table 1. As shown in Table 1 , anaerobic digestion of tofu-processing wastewater carried out in the batch system was operated under the acidic condition in which $\mathrm{pH}$ of the influent was 5.12. This indicated that the initial $\mathrm{pH}$ culture was quite far from the expected $\mathrm{pH}$ for operating the process of anaerobic digestion. The study revealed that to optimise and stabilise the process of anaerobic treatment for treating wastewater, $\mathrm{pH}$ culture should be maintained under the neutral level (Zhang et al., 2005).

Another study mentioned that when $\mathrm{pH}$ culture was under the acidic condition, the process of anaerobic treatment for removing organic materials would be restricted (Chen and Cheng, 2008). As the process of 
anaerobic treatment of tofu-processing wastewater was carried out under the acidic condition, the formation of methane gas as the end-product was inhibited. A study conducted by Liu et al. (2008) revealed that the activity of methanogens would completely be inhibited when pH culture was at about 5.5. This suggests that methanogens are very sensitive to the acidic condition (Liu et al., 2008). An inhibition of methanogen activity during methanogenesis process would significantly affect the degradation of organic wastes, and thereby would limit the process of organic removals during the anaerobic digestion.

\section{Table 1}

Anaerobic treatment performance operated in a batch mode

\begin{tabular}{c|c|c}
\hline Parameter & Influent & Effluent \\
\hline 1 & 2 & 3 \\
\hline $\mathrm{pH}$ & $5.12 \pm 0.02$ & $6.47 \pm 0.02$ \\
\hline $\mathrm{TDS}(\mathrm{ppm})$ & $1148.33 \pm 10.41$ & $1450 \pm 50$ \\
\hline $\mathrm{EC}(\mathrm{mS})$ & $2.3 \pm 0.02$ & $2.90 \pm 0.1$ \\
\hline $\mathrm{TS}(\%)$ & $1,07 \pm 0.09$ & $0.50 \pm 0.11$ \\
\hline $\mathrm{VS}(\%)$ & $68.99 \pm 1.051$ & $48.91 \pm 3.86$ \\
\hline $\mathrm{COD}(\mathrm{mg} / \mathrm{L})$ & $7796.07 \pm 13.52$ & $7459.67 \pm 175.42$ \\
\hline $\mathrm{TKN}(\mathrm{mg} / \mathrm{L})$ & $338.54 \pm 2.13$ & $276.67 \pm 33.83$ \\
\hline $\mathrm{P}(\mathrm{mg} / \mathrm{L})$ & $48.21 \pm 1.99$ & $46.00 \pm 5.29$ \\
\hline $\mathrm{K}(\mathrm{mg} / \mathrm{L})$ & $537.47 \pm 7.07$ & $597.67 \pm 28.04$ \\
\hline
\end{tabular}

Since the collected tofu-processing wastewater loaded into the anaerobic digester had been already in the acidic condition ( $\mathrm{pH}$ 5.2) as shown in the influent sample (Table 1), the anaerobic acidification process would occur in which the acidogenic microbes would dominate the digestion process ( $\mathrm{Li}$ et al., 2011). Some studies also revealed that $\mathrm{pH}$ between 4.0 and 5.0 could stimulate the growth of acid-forming microbes (Ye et al., 2007; Rhee et al., 2011; Darwin et al., 2018b). Further, the acidic condition could alsostimulate the growth of acidogenic bacteria to convert soluble organics into organic acids (i.e., volatile fatty acid and lactic acid), and thereby could increase proton concentration in the anaerobic culture and lead to the drop of pH (Darwin et al., 2018b; Wang et al., 2014). Once pH of the culture was too low $(\mathrm{pH}<6.0)$, the acidification process would naturally occur in the anaerobic digester (Darwin et al., 2018b; Zhu and Béland, 2006). Thus, anaerobic digestion operated under the acidic condition ( $\mathrm{pH}$ 5.0) could enhance the acid build up in the digester, and finally may screw up the process of biogas production.

In this present study, during the process of anaerobic digestion, $\mathrm{pH}$ culture was not adjusted or buffered through the addition of alkaline solution. Thus, the drop of $\mathrm{pH}$ in the anaerobic culture may induce the acid-forming microbes to grow and produce organic acids (Darwin et al., 2018b). The acidic conditions (pH $<6.0$ ) could inhibit the growth of methanogens (Batstone et al., 2002), and thereby could lower the yields and the production of methane gas as the end-product (Chen and Cheng, 2008). In this current study, an interesting thing occurred in the batch process in which after 4 days of incubation the biogas was continuously produced. As shown in Table 1, pH effluent was about 6.5 indicating that during the anaerobic digestion operated in the batch mode $\mathrm{pH}$ culture could increase naturally, and thereby could stimulate anaerobic microbes to produce biogas as the end-product.

The results of the study showed that anaerobic digestion of tofu-processing wastewater under the batch operation could produce $950 \mathrm{~mL}$ of biogas at 15 days of incubation (Fig. 1). This indicated that the production of biogas still occurred even if the culture was acidic. This happened due to the fact that during the process $\mathrm{pH}$ was recovered or increased from about

\section{Fig. 1}

Cumulative biogas production under batch operation

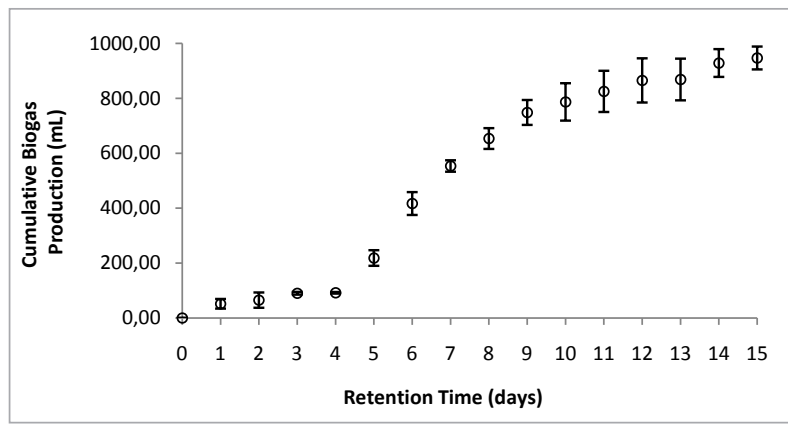


5.0 to 6.5 (Table 1). This result is also in agreement with the study by Cho et al. (1995) who found that $\mathrm{pH}$ increased and recovered after a few days of digestion that could be attributed to the decrease of organic acid concentration in the culture.

\section{Fig. 1}

Cumulative biogas production under batch operation

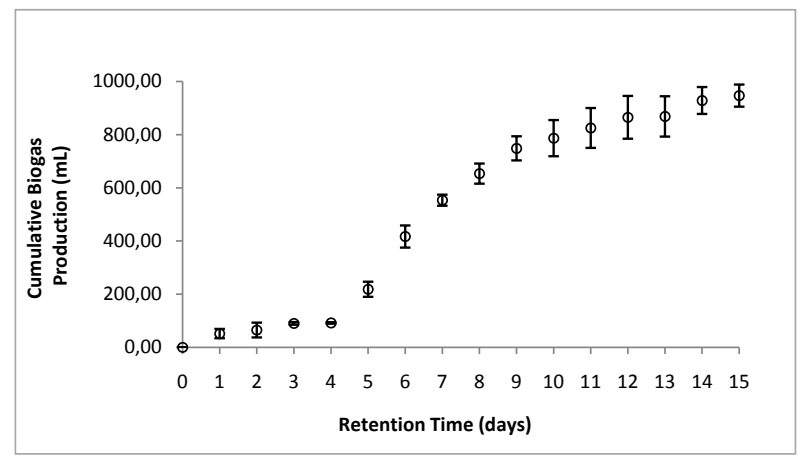

The results also showed a lag phase that occurred in the batch test and was quite long, i.e., about 4 days of incubation (Fig. 1). This could be caused by the acidic condition that may slow down anaerobic microbes to grow and convert organic wastes into end-products. This is in line with the study by Francois et al. (2007) revealing that low $\mathrm{pH}$ in a fermentation broth may cause a prolonged lag phase of microbial growth. The results of the current study suggested that the conversion of organic materials into biogas was inhibited by low pH.The study showed that low pH (pH 5.0-5.5) could suppress the growth of methanogens, and effectively inhibit methanogenic activity for cutting the production of biogas (Chae et al., 2010).

As no any other inoculum was added into the reactor, the activity of anaerobic biomass represented in the biogas production was also limited in the early stage of incubation. This is due to the fact that microbes might need some time to acclimatise with the anaerobic condition prior to conducting the conversion of substrates into the end-products. In this current study, the lag phase occurring within 4 days of incubation could be attributed to the microbial growth cycle represented with the time period needed for microbes to adapt to a new environment prior to commencing cell multiplication (Robinson et al., 2001). In this condition, microbes needed some time to adapt from the aerobic into the anaerobic condition.

The results of the present study showed that the limitation of anaerobic microbe activity in the early stage of fermentation was not only caused by the culture that had not been adapted to the anaerobic condition previously, but the inhibition might have also been aggravated by acidity in the culture $(\mathrm{pH}<5.5)$. The study conducted by Bouallagui et al. (2005) revealed that inhibition in the process of anaerobic digestion for biogas production was observed when $\mathrm{pH}$ in the anaerobic culture fell to 5 . This is in line with the study conducted by Hu et al. (2004) revealing that the percentage of substrate degradation decreased when $\mathrm{pH}$ culture was lower than 5.8.

\section{Continuous operation}

The results from the batch tests showed that anaerobic digestion of tofu-processing wastewater did not perform sufficiently well due to low $\mathrm{pH}$. The acidic conditions extended the lag phase period in the batch reactor, and inhibited the conversion of organic materials to form biogas. In the real wastewater treatment plant, the anaerobic digester would receive a continuous supply of wastewater. Thus, an effective method for operating the continuous system of the anaerobic digester would be required in order to have the capability to treat wastewater daily. To evaluate whether continuous feeding of wastewater could help recover the acidic culture into an acceptable level of $\mathrm{pH}$, anaerobic digestion of tofu-processing wastewater was carried out in a continuous mode. In this experiment, the short HRT of 10 days was applied in order to speed up the change and recovery of the acidic culture in the anaerobic digester.

The results showed that anaerobic digestion of tofu-processing wastewater operated in a semi-continuous mode could increase pH from 5.16 to 6.56 (Table 2). Even if pH culture was still in the acid level or below than neutral level, it was in the range of tolerated $\mathrm{pH}$ ( $\mathrm{pH}$ 6.5-8.0) for operating anaerobic digestion (Cioabla and lonel, 2012). The study revealed that the optimum $\mathrm{pH}$ for operating anaerobic digestion was in a range of 6.8 up to 7.2 (Cioabla and lonel, 2012). In this current study, continuous operation applied in 
the process of anaerobic digestion of tofu-processing wastewater was to shorten the lag phase from 4 to 2 days of incubation, and thereby could increase and/or speed up the production of biogas.

\section{Table 2}

Anaerobic treatment performance operated in a semi-continuous mode

\begin{tabular}{l|c|c}
\hline \multicolumn{1}{c|}{ Parameter } & Influent & Effluent \\
\hline \multicolumn{1}{c|}{1} & 2 & 3 \\
\hline $\mathrm{pH}$ & $5.16 \pm 0.03$ & $6.56 \pm 0.01$ \\
\hline $\mathrm{TDS}(\mathrm{ppm})$ & $1146.67 \pm 16.07$ & $1411.67 \pm 20.21$ \\
\hline $\mathrm{EC}(\mathrm{mS})$ & $2.31 \pm 0.17$ & $2.80 \pm 0.04$ \\
\hline $\mathrm{TS}(\%)$ & $1.08 \pm 0.095$ & $0.40 \pm 0.03$ \\
\hline $\mathrm{VS}(\%)$ & $69.60 \pm 0.73$ & $35.64 \pm 0.58$ \\
\hline $\mathrm{COD}(\mathrm{mg} / \mathrm{L})$ & $7796.40 \pm 17.12$ & $4807.95 \pm 244.8$ \\
\hline $\mathrm{TKN}(\mathrm{mg} / \mathrm{L})$ & $336.32 \pm 5.23$ & $208.28 \pm 1.81$ \\
\hline $\mathrm{P}(\mathrm{mg} / \mathrm{L})$ & $44.88 \pm 0.77$ & $65.39 \pm 3.57$ \\
\hline $\mathrm{K}(\mathrm{mg} / \mathrm{L})$ & $540.71 \pm 2.44$ & $372.76 \pm 4.09$ \\
\hline
\end{tabular}

The results also revealed that the continuous system produced more than double of biogas $(2770 \mathrm{~mL})$ in comparison with biogas produced under the batch operation (Fig. 2). The results suggested that the continuous operation was able to recover $\mathrm{pH}$ culture from the acidic condition into the appropriate level for operating anaerobic digestion. This indicated that the changes in the anaerobic culture caused by loading and wasting wastewater in the continuous system would be able to minimise the acid build-up

Fig. 2

Cumulative biogas production and $\mathrm{pH}$ in semi-continuous operation

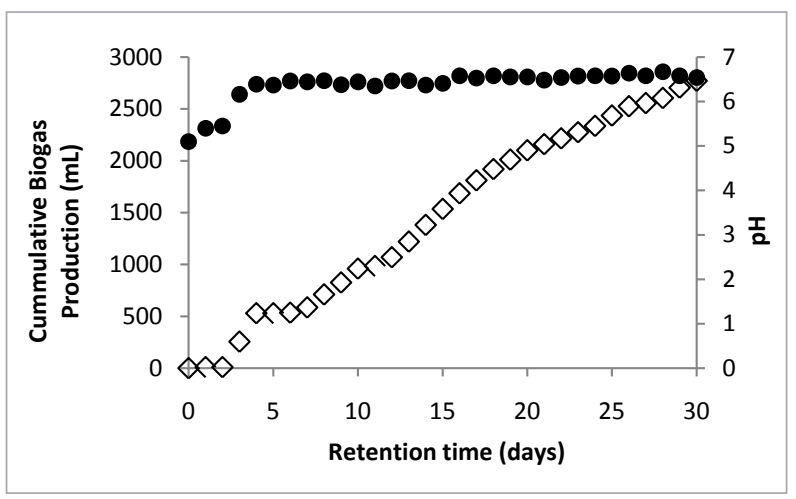

that would generate toxicfor the anaerobic microbial cultures. The results of the current study are quite different from the study conducted by Bouallagui et al. (2005)finding that anaerobic digestion operated with the short HRT could not maintain the $\mathrm{pH}$ level in which they found that when HRT was shifted from 20 to 10 days, $\mathrm{pH}$ dropped from 7 to 5 . The difference occurred due to the fact that the present study started the anaerobic digestion with HRT of 10 days while the previous study initiated the anaerobic process with the HRT of 20 days and shifted it into 10 days.

\section{Biodegradation efficiency}

The digestibility of organic wastes loaded into the anaerobic digester is an important parameter used to determinethe effectiveness of conversion and the quantity of biogas produced during the process of anaerobic digestion (Wilkie, 2005). Besides, Mata-Alvarez et al. (2000)mentioned that some criteria used for determining the success of anaerobic digestion included volatile solid (VS) reduction, total gas production and gas yield. In this current study, the efficiency of biodegradation was evaluated in both batch and continuous operations. The summary of the digestion efficiency is presented in Table 3.

\section{Table 3}

Efficiency of digestion

\begin{tabular}{|l|c|c|}
\hline \multicolumn{1}{|c|}{ Parameter } & $\begin{array}{c}\text { Semi-continuous } \\
\text { reactor }\end{array}$ & $\begin{array}{c}\text { Batch } \\
\text { reactor }\end{array}$ \\
\hline Total Biogas Production $(\mathrm{mL})$ & 2 & 3 \\
\hline Biogas yield (mL/g VS) & 2770 & 947 \\
\hline Volatile solids reduction (\%) & 722.84 & 42.76 \\
\hline COD removal (\%) & 38.81 & 56.97 \\
\hline
\end{tabular}

The results of the experiments showed that the continuous system produced almost three times higher biogas yield ( $123 \mathrm{~mL} / \mathrm{g}$ VS) in comparison with the biogas yield generated in batch operation ( $43 \mathrm{~mL} / \mathrm{g} \mathrm{VS}$ ). High biodegradation efficiency of anaerobic digestion of tofu-processing wastewater was also determined by the percentage of volatile solid reduction. The results showed that the continuous reactor had a higher 
percentage of volatile solid reduction (76\%) in comparison with the batch digester, which had only $57 \%$ of volatile solid reduction. This current result is quite close to the study conducted by Schieder et al. (2000) who successfully reached $80 \%$ of VS reduction from the process of anaerobic digestion of organic wastes. Overall, the results of the present study suggested that anaerobic digestion of tofu-processing wastewater operated in the continuous operation performed sufficiently well in reducing the organic contents even if the processing rate was increased by applying short HRT and high organic loading rate. The results suggested that the continuous operation could recover the acidic culture into close to the neutral condition required for optimising the process of anaerobic treatment.

\section{Conclusions}

Anaerobic digestion was an effective method used for treating tofu-processing wastewater in which both

\section{References}

Adekunle K.F., Okolie, J.A. (2015). A review of biochemical process of anaerobic digestion. Advances in Bioscience and Biotechnology, 6(03): 205-212. https://doi.org/10.4236/ abb.2015.63020

Alkaya, E., Demirer, G.N. (2011) Anaerobic acidification of sugarbeet processing wastes: effect of operational parameters. Biomass Bioenergy, 35(1): 32-39. https://doi.org/10.1016/j. biombioe.2010.08.002

APHA, (2012) Standard Methods for the Examination of Water and Wastewater, American Public Health Association, Washington, D.C. U.S.A.

Batstone, D.J., Keller, J., Angelidaki, I., Kalyuzhnyi, S. V., Pavlostathis, S. G., Rozzi, A., Vavilin, V. A. (2002) The IWA anaerobic digestion model no 1 (ADM1). Water Science and technology, 45(10): 65-73. https://doi.org/10.2166/wst.2002.0292

Bouallagui, H., Touhami, Y., Cheikh, R.B., Hamdi, M. (2005) Bioreactor performance in anaerobic digestion of fruit and vegetable wastes. Process biochemistry, 40(3-4): 989-995. https:// doi.org/10.1016/j.procbio.2004.03.007

Burkholder, J., Libra, B., Weyer, P., Heathcote, S., Kolpin, D., Thorne, P. S., Wichman, M. (2007) Impacts of waste from con- reactors of continuous and batch systems used could effectively reduce organic wastes and convert into biogas even if the influent was too acidic $(\mathrm{pH} 5)$. The continuous reactor performed better than the batch reactor in terms of biodegradation efficiency obtained. Based on the experiments, the continuous reactor produced a higher biogas yield and total production of biogas in comparison with the batch digester. Short HRT of 10 days and high OLR applied in the continuous reactor did not inhibit the process of anaerobic digestion in which after 4 days of incubation $\mathrm{pH}$ was recovered from 5.16 to 6.5 .

\section{Acknowledgments}

The authors acknowledge the financial support provided by Syiah Kuala University, Banda Aceh, Indonesia through the programme of community services with a product base coordinated by the Institute for Research and Community Services, UNSYIAH.

centrated animal feeding operations on water quality. Environmental health perspectives, 115(2): 308-312. https://doi. org/10.1289/ehp.8839

Cabral, J.P. (2010) Water microbiology. Bacterial pathogens and water. International journal of environmental research and public health, 7(10): 3657-3703. https://doi.org/10.3390/ ijerph7103657

Carucci, G., Carrasco, F., Trifoni, K., Majone, M., Beccari, M. (2005) Anaerobic digestion of food industry wastes: effect of codigestion on methane yield. Journal of Environmental Engineering, 131(7): 1037-1045. https://doi.org/10.1061/ (ASCE)0733-9372(2005)131:7(1037)

Chae, K.J., Choi, M.J., Kim, K.Y., Ajayi, F F., Park, W., Kim, C.W., Kim, I.S. (2010) Methanogenesis control by employing various environmental stress conditions in two-chambered microbial fuel cells. Bioresource Technology, 101(14): 5350-5357. https:// doi.org/10.1016/j.biortech.2010.02.035

Chae, K.J., Jang, A.M.,Yim, S.K., Kim, I.S. (2008)The effects of digestion temperature and temperature shock on the biogas yields from the mesophilic anaerobic digestion of swine manure. Bioresource Technology, 99(1): 1-6. https://doi. org/10.1016/j.biortech.2006.11.063 
Chen, Y., Cheng, J.J., Creamer, K.S. (2008) Inhibition of anaerobic digestion process: a review. Bioresource Technology, 99(10): 4044-4064. https://doi.org/10.1016/j.biortech.2007.01.057

Cho, J. K., Park, S. C., Chang, H. N. (1995) Biochemical methane potential and solid state anaerobic digestion of Korean food wastes. Bioresource Technology, 52(3): 245-253. https://doi. org/10.1016/0960-8524(95)00031-9

Cioabla, A.E., Ionel, I., Dumitrel, G.A., Popescu, F. (2012) Comparative study on factors affecting anaerobic digestion of agricultural vegetal residues. Biotechnology for biofuels, 5(39): 1-9. https://doi.org/10.1186/1754-6834-5-39

Chukwu, 0. (2009) Impacts of food processing industry on some environmental health and safety factors. Caspian Journal of Environmental Sciences, 7(1): 37-44.

Darwin, Charles, W., Cord-Ruwisch, R. (2018a) Concurrent Lactic and Volatile Fatty Acid Analysis of Microbial Fermentation Samples by Gas Chromatography with Heat Pre-treatment. Journal of Chromatographic Science, 56(1):1-5.

Darwin, Barnes, A., Cord-Ruwisch, R. (2018b) In vitro rumen fermentation of soluble and non-soluble polymeric carbohydrates in relation to ruminal acidosis. Annals of Microbiology, 68(1): 1-8. https://doi.org/10.1007/s13213-017-1307-x

Darwin, Fazil A., Ilham, M., Sarbaini, Purwanto, S. (2017)Kinetics on anaerobic co-digestion of bagasse and digested cow manure with short hydraulic retention time. Research in Agricultural Engineering, 63(3):121-127. https://doi.org/10.17221/18/2016RAE

Darwin, Cheng, J.J., Gontupil J., Liu, Z. (2016a) Influence of total solid concentration for methane production of cocoa husk co-digested with digested swine manure. International Journal of Environment and Waste Management, 17(1): 71-90. https:// doi.org/10.1504/IJEWM.2016.076432

Darwin, Cheng, J.J., Liu, Z., Gontupil, J. (2016b) Anaerobic co-digestion of cocoa husk with digested swine manure: evaluation of biodegradation efficiency in methane productivity. Agricultural Engineering International: The CIGR Journal, 18(4): 147-156.

Darwin, Cheng, J.J., Liu, Z., Gontupil, J., Kwon, O.S. (2014) Anaerobic co-digestion of rice straw and digested swine manure with different total solid concentration for methane production. International Journal of Agricultural and Biological Engineering, 7(6): 79-90.

Francois, K., Valero, A., Geeraerd, A. H., Van Impe, J. F., Debevere, J., García-Gimeno, R. M., Devlieghere, F. (2007) Effect of preincubation temperature and $\mathrm{pH}$ on the individual cell lag phase of Listeria monocytogenes, cultured at refrigeration temperatures. Food Microbiology, 24(1): 32-43. https://doi. org/10.1016/j.fm.2006.03.011
Gontupil J., Darwin Z., Liu J.J., Cheng, Chen H. (2012) Anaerobic co-digestion of swine manure and corn stover for biogas production, In: Proceedings of the ASABE Annual International Meeting Conference, Dallas, USA 29 July -1 August, 2012, pp. 1342-1347. https://doi.org/10.13031/2013.41776

González-Fernández, C., Sialve, B., Bernet, N., Steyer, J.P. (2013) Effect of organic loading rate on anaerobic digestion of thermally pretreatedScenedesmus sp. biomass. Bioresource Technology, 129: 219-223. https://doi.org/10.1016/j.biortech.2012.10.123

Gyawali, S.,Techato, K., Yuangyai, C. (2012) Effects of industrial waste disposal on the surface water quality of U-tapao River, Thailand.Proceeding of International Conference on Environment Science and Engieering, 3: 109-113.

Hu, Z. H., Wang, G., Yu, H. Q. (2004) Anaerobic degradation of cellulose by rumen microorganisms at various $\mathrm{pH}$ values. Biochemical Engineering Journal, 21(1): 59-62. https://doi. org/10.1016/j.bej.2004.05.004

Islam, M., Morgan, J., Doyle, M.P., Phatak, S.C., Millner, P., Jiang, X. (2004) Persistence of Salmonella entericaserovarTyphimurium on lettuce and parsley and in soils on which they were grown in fields treated with contaminated manure composts or irrigation water. Foodborne Pathogens \& Disease,1(1): 27-35. https://doi.org/10.1089/153531404772914437

Joanne, K.P. (1991) Applied Math for Wastewater Plant Operators. CRC Press. New York, U.S.A.

Kanu, I., Achi, O.K. (2011) Industrial effluents and their impact on water quality of receiving rivers in Nigeria. Journal of applied technology in environmental sanitation, 1(1): 75-86.

Lay, C.H., Sen, B., Huang, S.C., Chen, C.C., Lin, C.Y. (2013) Sustainable bioenergy production from tofu-processing wastewater by anaerobic hydrogen fermentation for onsite energy recovery. Renewable energy, 58: 60-67. https://doi.org/10.1016/j. renene.2013.03.01

Li, Y., Park, S. Y., Zhu, J. (2011) Solid-state anaerobic digestion for methane production from organic waste. Renewable and sustainable energy reviews, 15(1): 821-826. https://doi. org/10.1016/j.rser.2010.07.042

Lim, B.S.; Kim, B.C.; Chung, I., (2012) Anaerobic treatment of food waste leachate for biogas production using a novel digestion system. Environmental Engineering Research, 17(1): 4146. https://doi.org/10.4491/eer.2012.17.1.041

Liu, D., Zeng, R. J., Angelidaki, I. (2008) Effects of pH and hydraulic retention time on hydrogen production versus methanogenesis during anaerobic fermentation of organic household solid waste under extreme-thermophilic temperature $\left(70^{\circ} \mathrm{C}\right)$. Biotechnology and Bioengineering, 100(6): 1108-1114. https:// doi.org/10.1002/bit.21834 
Mata-Alvarez, J., Mace, S.,Llabres, P.(2000) Anaerobic digestion of organic solid wastes. An overview of research achievements and perspectives. Bioresource Technology, 74(1): 3-16. https:// doi.org/10.1016/S0960-8524(00)00023-7

Mir, M.A., Hussain, A., Verma, C. (2016) Design considerations and operational performance of anaerobic digester: A review. Cogent Engineering, 3(1): 1. https://doi.org/10.1080/23311916 .2016 .1181696

Parawira, W., Read, J.S., Mattiasson, B., Bjornsson, L. (2008) Energy production from agricultural residues: high methane yields in pilot-scale two-stage anaerobic digestion. Biomass and Bioenergy, 32: 44-50. https://doi.org/10.1016/j.biombioe.2007.06.003

Rhee, S.J., Lee, J.E., Lee, C.H. (2011) Importance of lactic acid bacteria in Asian fermented foods. Microbial Cell Factories, Vol. 10(1): 5. https://doi.org/10.1186/1475-2859-10-S1-S5

Robinson, T. P., Aboaba, O. O., Kaloti, A., Ocio, M. J., Baranyi, J., Mackey, B. M. (2001) The effect of inoculum size on the lag phase of Listeria monocytogenes. International journal of food microbiology, 70(1-2): 163-17. https://doi.org/10.1016/S01681605(01)00541-4

Schieder, D., Schneider, R., Bischof, F. (2000) Thermal hydrolysis (TDH) as a pretreatment method for the digestion of organic waste. Water Science and Technology, 41(3): 181-187. https:// doi.org/10.2166/wst.2000.0070
Solomon, E.B., Yaron, S., Matthews, K.R. (2002) Transmission of Escherichia coli 0157: H7 from contaminated manure and irrigation water to lettuce plant tissue and its subsequent internalization. Applied and environmental microbiology, 68(1): $397-$ 400. https://doi.org/10.1128/AEM.68.1.397-400.2002

Wang, K., Yin, J., Shen, D., Li, N. (2014) Anaerobic digestion of food waste for volatile fatty acids (VFAs) production with different types of inoculum: effect of $\mathrm{pH}$. Bioresource Technology, 161: 395-401. https://doi.org/10.1016/j.biortech.2014.03.088

Wilkie, A.C. (2005) Anaerobic digestion of dairy manure: Design and process consideration. Natural Resource,Agriculture, and Engineering Service, 176: 301-312.

Ye, N.F., Lü, F., Shao, L.M., Godon, J.J., He, P.J. (2007) Bacterial community dynamics and product distribution during $\mathrm{pH}$-adjusted fermentation of vegetable wastes. Journal of Applied Microbiology, 103(4): 1055-1065. https://doi.org/10.1111/j.13652672.2007.03321.x

Zhang, B., Zhang, L.L., Zhang, S.C., Shi, H.Z., Cai, W.M. (2005) The influence of $\mathrm{pH}$ on hydrolysis and acidogenesis of kitchen wastes in two-phase anaerobic digestion. Environmental Technology, 26(3): 329-340. https://doi.org/10.1080/09593332608618563

Zhu, H., Béland, M. (2006) Evaluation of alternative methods of preparing hydrogen producing seeds from digested wastewater sludge. International Journal of Hydrogen Energy, 31(14): 1980-1988. https://doi.org/10.1016/j.ijhydene.2006.01.019 